\title{
Collaborative approaches in Initial Teacher Education: lessons from approaches to developing student teachers' use of the Internet in science teaching
}

\begin{abstract}
In many countries, governments are keen to persuade teachers at all levels to seek to enhance the learning of their students by incorporating Information and Communication Technologies (ICT) within their classrooms. This paper reports on the development of collaborative approaches to supporting use of the Internet by Post Graduate Certificate of Education (PGCE) science students on Initial Teacher Education (ITE) courses in England, drawing on data from five Higher Education Institution (HEI) - school partnerships across four years. A mixed method approach has been used, involving questionnaires, structured interviews, lesson observations and case studies. The outcomes of the first three years identified barriers to practice and suggested the need to develop more collaborative approaches to development. The focus of this paper is on examining ways in which university faculty tutors and mentors or co-operating teachers can work together with students on PGCE courses in developing practice. The lessons from this focus on the Internet, no longer a new technology, has enabled us to identify implications for HEI partnerships in ITE and suggests a need to further collaborative structures in order to support and develop practices, including those involving the innovative use of new technologies in the post-industrial society.
\end{abstract}

Keywords: ICT; teacher education; collaboration; professional development

\section{Introduction}

For a long period of time governments in many countries have put developments in the use of ICT to support teaching and learning high on their agendas. Kozma (2009), in a comparative analysis of international policies, notes arguments for this emphasis linked strongly to education reform and leading to initiatives designed to develop the ICT skills of both beginning and in-service teachers spanning all continents. England has been no 
exception in this regard, with detailed national standards for beginning teachers appearing in 1998 (DfEE 1998) coupled with training given to all in-service teachers over the following three year period (NOF 2002), various online teacher support initiatives (e.g. NGfL 2002) and standards developed for all teachers in the profession that required effective use of ICT (TDA 2007). In recent years, alongside conferences dedicated to the promotion of ICT in education, various international meetings and symposia have sought to further development, especially since the advent of Web 2.0 technologies. Symposia involving representatives from across the world, including European Schoolnet (linking 31 Ministries of Education in Europe), The Consortium for School Networking (COSN) in the USA and Educationau (the Australian national agency for innovation in education) have led to policies and declarations of intent designed to help deliver the 'promise of ICT in education' (European Schoolnet 2010, 29).

Support for the use of ICT in schools has come from a growing body of research showing that those which make good use of ICT tend to be more successful and such studies often make particular reference to the affordances provided by the Internet (Becta 2001, 2002; DfES 2003; Osborne and Hennessy 2003). However, there have also been some questions raised concerning the benefits of the use of computers in schools and some of these point to worries about ineffective use of the Internet (e.g. Cordes and Miller 2000; Brabazon 2002). It is also clear that historically there has been a slow uptake of ICT in some schools, with science being no exception in this regard (Poole 2000).

In seeking to support the use of ICT in UK schools, a lot of money has been allocated to the development of ICT facilities. Thus by $2003,86.5 \%$ of computers in secondary school were already connected to the Internet, an average of about 150 per school, more than five times those available in 1999 (DfES 2003). However, detailed research findings continued to 
show that many teachers still lacked confidence in their use of ICT (Selinger and Austin 2003) and such evidence mirrored that found by investigators in other parts of the world (e.g. Kirshner and Selinger 2003). It is also interesting to note that the 2003 Department for Education and Skills (DfES) survey found that only 57\% of teachers were making regular use of ICT in their subject teaching, a figure that had remained fairly static for two years. The DfES survey did not probe into the nature of such use in depth, but the numbers making regular use directly in the classroom were likely to be significantly lower than $57 \%$. The limited use of the Internet in schools was supported by data in the final report from the major large-scale, government-funded, Impact2 study (Harrison et al. 2003), which noted that for secondary aged pupils $(11-16$ year olds $)$ the most common answer to how often pupils used the Internet in lessons was 'never' and the combined figures for 'hardly ever' and 'never' averaged over $80 \%$.

The challenges facing the practising teacher in respect of integrating new technology into their teaching are well documented (e.g. Ruthven, Hennessy and Deaney 2005; White 2000). These challenges mean that even those willing to embrace change often face pressures of time and lack of resources or training which militate against development. Set against such challenges, it is no surprise to find that research shows that, far from leading to major shifts in pedagogical practices, the technology itself is moulded to current practice (Goodson and Mangan 1995). This can probably be further understood if the initiative appears to be led by the technology and comes from the kind of top down decision making prevalent in some countries, of which England is an example. In such circumstances teachers are unlikely to embrace the possibility of changing pedagogies, especially since there has been little tradition of discussing pedagogy in English schools. Simon's (1980) paper on the issue of lack of attention to pedagogy probably continues to remain true in many schools, although there is 
some more recent evidence suggesting that subject departments in secondary schools in certain specific circumstances do collaborate to develop their subject knowledge and pedagogical content knowledge (see, for example, Burn, Childs and McNicholl 2007).

A further problem is that the models adopted in curriculum development programs have often been of a transmissive, top down nature, which can be seen as a contradiction in terms to some of the ways the instruments themselves are intended to be used to support and, indeed, transform teaching and learning. This top down approach was true of many of the training models designed to support practising teachers' use of ICT (NOF 2002). Thus all teachers in the UK were given training to bring themselves up to at least the standards expected of new entrants to the profession. The approach adopted often involved a large quantity of materials being delivered to teachers who were expected to work through them in a very instrumental manner, with technical issues paramount. It comes as no surprise that these were regarded as largely ineffective, even by the government who had invested so much in them. However, the lessons learned here showed that for practising teachers the challenges for change are great, so it is all the more so for beginning teachers facing a multitude of challenges and fears. The issues identified through NOF training have also been wellrehearsed in other studies (Jackson-Mistler and Songer 2000; White 2000). An exception to some rather poorly received NOF training schemes was that provided by the Science Consortium, which adopted a more collaborative, constructivist approach, requiring work with whole departments and building on current departmental practice (Rogers and Finlayson 2003). Such approaches give attention to the individual and local needs, in agreement with the arguments presented by Fullan (2000), who noted that many of the national level, systemic reforms being implemented in various places had failed to give attention to such needs. 
The slow progress in development in use of the Internet outlined above provided the impetus for our research. Thus, as teacher educators we were concerned to ensure that our students had an understanding of the debates concerning its use as a tool for teaching and learning, how such debates might inform use, the technical skills required and any pedagogical issues specific to the Internet. This is all set against the background outlined, with limited understanding of the teaching and learning issues associated with the Internet, limited use within schools, but strong pressure from government agencies and inspection regimes to develop 'competence' in order to meet defined standards. The balance between promoting effective use of the Internet while maintaining critical engagement with issues concerning the adoption of new technologies, including the analyses of their affordances and potential to transform practice through changes to curriculum and pedagogical approaches, is a difficult one. While the thrust of the paper is concerned with development issues it is important to stress that the courses continue to seek to engage critically with prevailing orthodoxies within their overall structures.

While this paper looks in particular at Internet use, we believe that the lessons learned are relevant to the adoption of other new technologies, as well as to approaches to the professional development of teachers in general. There have been some more positive national trends in use of the Internet over the period of this research. However, in their last two 'harnessing technology' reports for schools, Becta $(2009,2010)$ found that fewer than 10 per cent of students in secondary schools were making use of any form of technology in core subjects at least once a week and there remained a long tail of slow adopters of new technologies in general. Clearly, the Internet is no longer a new technology and the focus of such national reports has moved to consider more sophisticated uses of a range of technologies, many dependent on the Internet. What is apparent in this national data is that 
significant numbers of teachers and schools remain slow in harnessing the potential of such technologies and further reviews of research continue to indicate very uneven development across schools and a need to recognise that 'using ICT effectively in schools is about more than changing resources; it is about changing practices and culture' (Condie and Munro 2007, 8). The need to move away from top-down imposed policy decisions and technocentric models for ICT adoption and focus more on 'specific pedagogical dimensions' (Jimoyiannis and Komis 2007, 170) has been recognised across cultures. Reviews to help those seeking to support developments in ICT use in developing countries note 'an enduring problem: putting technology before education' (Trucano 2005).

\section{Research Framework}

In seeking to respond to the concerns about the preparation of student teachers for use of the Internet, a group of science tutors in five partnerships of schools and HEIs in England engaged in a series of linked research and development projects over a four year period. The work involved a number of stages where the research design was developed in response to successive outcomes in an iterative manner. The overarching aims of the work for each stage have been:

Cohort 1:

1. examine the starting competences and attitudes to the use of the Internet of student science teachers;

2. identify barriers to student teachers' progress in the use of the Internet with pupils in the classroom;

3. examine models of practice in use of the Internet;

use these outcomes to: 
4. develop models of support which seek to overcome the barriers identified;

5. develop and share models of effective pedagogical practice.

Cohorts 2-3: repeat the process; refine research tools and examine progress since cohort 1.

Cohort 4: repeat the process as for cohorts 2 and 3; increase emphasis on the role of the mentor or co-operating teacher working in collaboration with the HEI and student teacher; examine trends over the four year period.

Thus the overall purposes involved researching student teachers' use of the Internet, examining pedagogical issues in order to try to identify effective practice and developing strategies to improve use.

In this paper we focus mainly on case study data from cohort four. The aim was to see how far particular collaborative course approaches and support activities, developed in the light of the professional development literature and the outcomes with earlier cohorts, were impacting on the practice. In this way we aimed to identify further development needs for the course. However, we also re-analysed data from cohorts one to three to look at the development of collaborative practice in these cohorts as well, recognising that although collaboration was an explicit aim for cohort 4 , it was absent in previous cohorts.

\section{Context}

The five secondary (age 11-18) PGCE courses that provide the setting for the research are one year courses involving a partnership between an HEI and set of schools. The students spend 120 days in schools and 60 days in the HEI. The students are organised in cohorts for the HEI-based days and are normally placed as individuals or pairs within subject departments 
for the school-based days. There are a number of facets of the courses that are important in understanding the basis for developments in our work on the Internet. We outline these briefly below.

The PGCE courses have, as their basis, a social constructivist approach to learning. This draws on Vygotskian arguments which stress the importance of discourse in the promotion of learning (Vygotsky 1987). A key intention of the courses is to develop student teachers as reflective practitioners, in line with Schon's (1987) arguments. All five HEI partnerships place emphasis on developing collaborative practices involving the mentors, faculty tutors and student teachers working together. This includes co-teaching, involving mentors and student teachers working together in the classroom in seeking to develop their thinking (Roth and Tobin 2004) and student teachers working together in pairs or multiple placements on the practicum (Bullough et al. 2002; Sorensen and Sears 2005; Nokes et al. 2008).

The courses have also been influenced by Lave and Wenger's (1991) arguments for situating learning in forms of 'social co-participation', as skills are developed through engaging in processes within particular socio-cultural settings. However, some settings may not a value the skills to be developed or be able to provide the necessary support. Our early research on the Internet showed that there are many instances of the mentor and school hoping that the student teacher themselves would take a lead [names deleted to maintain integrity of review process]. Thus while it is the mentors who have been cited as being of key importance in supporting student teachers' developments across a variety of applications (see, for example, Galanouli and McNair 2001; Cuckle and Clarke 2002), problems are likely to arise if they do not have the necessary expertise. Clearly the mechanisms of support for Internet use 
need to reflect the variety of contexts and levels of development present in the practicum arrangements within partnerships.

The desire for student teachers to contribute to the school has brought a broader perspective to work with the Internet and accords with international studies which have shown that there are reciprocal benefits to be had from the student teacher-mentor relationship (Carrington 2004; Gilles and Wilson 2004; Menter et al. 2010). Historically, models of teacher education have had a tendency to separate initial preparation from continuing professional development (CPD). This situation has changed somewhat in recent years in England, initially through the introduction of standards (TDA 2007) for qualified teacher status (QTS), which needed to be maintained and built on in the first year of teaching and beyond. Alongside this the Teacher Training Agency (TTA) became the Training and Development Agency for Schools (TDA), with a remit to oversee the CPD of existing teachers as well as the recruitment and training of beginning teachers. More recently, following a change of government, the TDA has been replaced by the Teaching Agency (TA), which is now an arm of the Department for Education, and a new set of standards that apply to teachers at all stages of their careers has been developed (DfE 2012). While the political motives for such a change may not necessarily be directed towards deepening partnerships between HEIs and schools, the focus on standards that apply throughout careers continues to lend itself to models of professional development that do not treat ITE in isolation.

In developing partnership processes it has been important for us to draw on the literature concerning successful CPD models. Such analysis shows that CPD is most effective when there is a strong sense of ownership by those undertaking the CPD, is based on collaborative approaches within social contexts and has clearly defined roles for coaches and mentors (Cordingley et al. 2005). This is in accord with the advice of Bishop and Denley 
(2005), who argue that a collegial approaches embedded in a social context are generally the most effective and resonates with the views of Papaevripidou, Lividjis and Costas (2011) who advocate that engaging teachers in constructing a public artefact (e.g. their own curriculum) is a productive way to support their learning and its transformation into pedagogically potent curriculum designs.

Attention has been given to the key arguments outlined above in developing the processes and materials designed to support the student teachers' use of the Internet.

\section{Methodology}

The research is positioned within an interpretivist paradigm and a practitioner led action research tradition. Thus teacher educators have taken the lead in seeking to understand the practices and developments in the use of the Internet within their own HEI-schools partnerships. It has employed mixed methods in seeking to address the overall research aims. Within the latter phase of the research the focus has been on the use of collective case studies (Stake 2005), designed to enable us to gain deep insights into practices across partnerships and school settings. The questions we have been seeking to address are:

- What approaches and structures in HEI-schools partnerships have supported developments in use of the Internet?

- What has been the impact of the collaborative approaches to developments in use of the Internet?

- What lessons can be drawn from the longitudinal study of developments in use of the Internet for future developments in the use of new technologies in schools? 
The overall data have been drawn from five partnerships over four years and has included:

- questionnaires used with 598 students;

- $\quad$ structured interviews with between 1 and 3 students in each partnership over three years, making 34 in total;

- $\quad$ case studies based on the data from cohorts 2 and 3;

- lesson observations, some including video, conducted with 17 students;

- case studies of the 17 students who were observed teaching, 7 of which included interviewing mentors or co-operating teachers during the fourth year of the study.

Details of the questionnaire and structured interview approach used with cohorts 1-3 are reported in detail elsewhere [names deleted to maintain integrity of review process]. We reference them here as they provided a background to the case studies with cohort 4 and the longitudinal study.

The key change with cohort 4 was one of moving away from supporting the student separately to working more closely with mentors. This arose from the continuing evidence that Internet use within the schools did not appear to have changed much over three years and thus one of the main barriers that had originally been identified by the students, the lack of good role models and examples of effective practice in schools, remained an intransigent problem. Thus the arguments for developments in practice to be embedded in context made earlier were unlikely to be met without further collaborative practice bringing together tutors, student teachers and mentors. In seeking to support this, materials were developed in the light of the CPD principles analysed in the theoretical framework [names deleted to maintain integrity of review process]. A collaborative approach to the production and trialling of materials was adopted throughout. In the first instance, an analysis of case studies was carried 
out by faculty tutors in order to identify areas for development. Individual tutors then independently drafted training materials. These were further refined after being reviewed by others in the group. Further development, involving other tutors and student teachers, followed. Then, as part of their normal tutorial arrangements, student teachers were required to reflect upon their existing practice, identify areas for development and select the activities that best suited their individual needs. Sharing and discussion with mentors took place in each partnership using normal meeting structures. The hope was that the materials would help more knowledgeable mentors to support their mentees, who would have themselves identified learning needs, while also support less experienced mentors to develop their own expertise and, in some cases, learn from their student teachers. The research element of the work now involved visiting schools to observe lessons and interview both students and mentors.

The data collected with cohort 4 was interviews with mentors $(\mathrm{N}=7)$ and student teachers $(\mathrm{N}=17)$ and observations of practice in schools involving these mentors, other mentors and their student teachers $(\mathrm{N}=17)$. The mentors were a purposive sample, selected to include those who were already making a lot of use of the Internet as well as those keen to develop and analyse practice further. The interviews were analysed using content analysis to identify themes and observations of lessons and subsequent interviews compared to identify where issues had arisen and possible causes of problems in relation to fostering collaboration in supporting student teachers' use of the Internet. In addition, as indicated above, we were aware from previous case studies in cohorts 1-3 that there had been some previous levels of collaboration with mentors, so we also did further analysis of the earlier case studies to add to our findings. This allowed for categories of support and possible processes to be identified. Thus various approaches to overcoming particular barriers have been identified, drawing on actions taken following the initial research. 


\section{Findings}

The main focus of the findings and analysis is on how far the collaborative practices supported by the course procedures in general, and the support materials produced in particular, have furthered the developments in use of the Internet for cohort 4. In so doing it draws on a re-analysis of the initial work and outcomes (cohort 1); the case studies of practice (cohorts 2 and 3) and the longitudinal study (all cohorts).

Findings from the initial stages with cohort 1 showed that, alongside the expected concerns about the hardware, software, access, reliability and support systems in the schools, three other significant barriers to use of the Internet were identified:

1. a lack of knowledge of suitable sites and the huge range of sites available, which were of varying quality, making searching very time-consuming;

2. a lack of knowledge of what contributed to an effective web-based lesson;

3. a lack of sufficient role models within partnership schools who could provide student teachers with examples of and advice upon how to deliver suitable lessons.

In re-examining the questionnaires from this first cohort, fewer than $10 \%$ of students had seen mentors or co-operating teachers using the Internet. The interview data provided no evidence of students joint planning lessons involving Internet use and only one student referred to detailed evaluation of a lesson that had used the Internet. Indeed, it had been a struggle for 
many of the students to fulfil the basic expectations in terms of their use of the Internet in lessons.

In seeking to address all three barriers with cohorts 2 and 3, the HEIs had been promoting more systematic collaboration between student teachers and their mentors. The analysis of this questionnaire data showed that student teachers' perceptions of use by mentors had remained low. While the interviews and case studies with cohorts 2 and $3(\mathrm{~N}=$ 21) did show evidence of some more systematic approaches being adopted by student teachers, only two students, on one occasion, had completed a process with the mentors that involved planning, implementing and evaluating lessons. These students spoke very positively about the experience. Given that these interview and case study samples included mentors and co-operating teachers in partnership schools who were making more use of the Internet, it is likely that practice across the whole cohort was even more limited. Overall, then, it appears that barrier 3 remained largely untouched.

While the longitudinal analysis and case studies [names deleted to maintain integrity of review process] showed increasingly positive attitudes and more student teachers reporting on 'successful' use in the classroom, significant problems remained. The changes over this three year period did include some sharing of the work of the team with mentors, through mentors' input into working groups in some of the HEIs, which was designed to heighten awareness and raise expectations for the school practicum. However, it was clear from the data that the mentors remained very varied in their approach and felt that their roles and its relation to tutors' roles needed clarification. A clear theme identified through the analysis was the need for HEI tutors and mentors to work in a closer, more coordinated manner with student teachers. 
It was in an effort to respond to these issues and a perceived lack of progress that the further course changes were made for cohort 4 . Within each of the three barriers identified a number of themes and questions had been identified and it is these that led to the production of the materials through the processes described earlier. The issues identified and support activities produced can be seen in Table 1.

[Insert table 1 here]

More details of the tasks have been reported elsewhere [names deleted to maintain integrity of review process]. It is the principles that lie behind the activities that are important for the purposes of this paper. The aim was to enable students to work more closely with mentors through providing support activities that both could access. The materials were designed to be flexible so they could be applied in different ways in different contexts, within the available timeframes or needs of the students. No activities were compulsory. For example, in 'Understanding of different uses of the Internet to meet particular objectives' a number of ways of using the Internet are presented (e.g. research activities, modelling tools and simulations, live event and web quests) and students are asked to consider their affordances and evaluate how they might be used to meet particular objectives. Further tasks then help them to develop particular approaches (e.g. developing a web quest).

The case studies from cohort 4 provide a wealth of rich data in relation to the extent and perceived efficacies of the collaborative practices. We have presented examples from the data that are representative of particular trends or views in a manner that is integrated with the 
analysis. We have also identified the extent to which they were discernible in a number of contexts.

The findings from the case studies showed that there was strong support for the materials that had been developed. Thus all 7 mentors interviewed were positive about their potential and the relevance of the materials was agreed by all 17 student teachers. This would suggest that the collaborative approach taken to developing the materials had been successful. All the student teachers also liked the idea that the choice of activities was left to them and recognised the commitment to personalising support represented in this approach. In short, the work on this was valued in all the HEI partnerships.

Looking to use, there were clear examples of the materials helping to promote collaborative practice between student teachers and mentors. These included examples of detailed discussion of pedagogical issues and, in several instances, students and mentors reported on more lasting contributions to schemes of work in the department. As an example, in Case Study 4 the focus had been on the reliability of evidence within the scientific enquiry area of the science curriculum:

...we wanted them to get information from the internet.... a session at uni[versity] had looked at this and there was an activity [Uses of the Internet in science teaching]...I talked to my mentor (Interview: Student 4)...we talked together about information from the internet... a concern I raised was all the iffy stuff out there...he [Student 4] showed me an activity on this [Do you believe this website?]...we decided to plan a lesson around this...the main focus was on making judgements about the websites and what was on them (Interview: Mentor 4)...criteria for judging sites agreed through questioning...pupils on task...questioning indicated that most understood the objective 
of the lesson...when asked 10 of 12 pairs able to explain main objectives (Lesson Observation Notes Researcher 4)...on the whole the lesson worked well and we decided to build this into our scheme (Interview: Mentor 4)...I thought it went well...we discussed it together and made some changes he wanted for the scheme of work (Interview: Student 4).

This case study took place in the context of a school with a mentor who was committed to developing practice and aware that they were not, as he put it, 'at the forefront of developments'. He valued the support that the materials provided.

A feature of many case studies was that the presence of the activities had served as a spur to discussions and such discussions had enabled more effective practices to be developed:

...the activities gave us a focus (Interview: Student 7)

...to be honest, I don't think we'd have talked about it so much without having the activities to work with...I'm sure the lesson went better [as a result] (Interview: Mentor 2).

Where these deeper examples of collaboration occurred it was usually with the mentors who were already regular users or those who had expressed the desire to develop their own practice, as would be expected. Observations of the lessons described as 'successful' in these instances tended to support the views expressed in the interviews with the students and mentors. Thus much more depth could be seen in the conversations about the lessons and the kinds of judgements being made concerning effectiveness of approaches:

...I was a bit taken aback when I realised that the activity we had [only allowing named sites] did not really allow the students to research...safety was a big issue, so 
we gave them the sites to visit...when we discussed the activity on using the internet it made us think again and we changed things (Interview Mentor 1)...the school were worried but we made things clear to the pupils...how to search, checking sites, no 'cut and paste' etc...it worked well and I think they learned more about how to search... and they behaved! (Interview: Student 1).

The evidence showed that in some cases the materials had led to student teachers being able to work closely with mentors on developing skills and on occasion a mentor took a lead in sharing their own thoughts and expertise:

My mentor had developed a number of ways of using the Internet with pupils...she showed me some and we looked at the activities together...we taught two lessons together and compared evaluations (Interview: Student 16).

However, even within the 17 case studies for cohort four, engagement with the materials was quite limited. Thus most had only looked at one or two of the activities and in only about half the cases had this been accompanied by joint planning of lessons that drew on ideas from the activities. More of the students had used the materials as individuals or through work with other students in university. In accounting for some of this limited use, it is important to highlight constraints that had been identified with earlier cohorts. In particular those of time, support and technical problems. It was also clear that the work the students were doing was not generally seen as part of the departments' own development needs or priorities. In line with this, the questionnaire data from the students in this cohort indicated no significant increase in student teachers' perceptions of use of the internet by teachers, even in these case study schools. 
The researchers, as in previous years, were very conscious that they might be being told what they wanted to hear. However, every effort was taken to avoid this, including explicitly sharing the worry while collecting the data and engaging the students in the research at a meta-level. While we cannot be certain that all students and mentors expressed their views openly, it has been the case that they have been prepared to be critical of other course procedures in each cohort and the collection of some data after the end of the course sought to minimise any fears of negative criticism rebounding on individuals. The research gained ethical approval from all the institutions involved.

\section{Conclusions and implications}

There have been some encouraging developments in practice across the partnerships over the four years of the research project. Whilst acknowledging that this research has not attempted any systematic approach in seeking to examine cause and effect in terms of the increased usage and positive attitudes of the students, it does appear from the case studies that collaborative approaches are having an impact. However, the pace of change is slow, reflecting the complexity of the issues that have been indicated in the literature for some time (e.g. Scanlon 1997; Clarke and Slotta 2000; Jackson-Mistler and Songer 2000; White 2000;).

The issues that we have identified include many that are generic and some that are specific to the technology. In generic terms there are important structural issues in relation to the organisation of ITE courses, including the practicum, and role issues in relation to facultybased tutors and school-based mentors and co-operating teachers. There are also issues of how the course content is organised and the approach to understanding of pedagogy. This latter area, as we have seen, brings in specific issues in relation to technology. The decisions 
about how best to support development are then underpinned by what we understand about effective CPD. We consider these issues and their implications below.

In terms of technology, our research reflects that of others working in the field in pointing to a need to develop our pedagogical understandings further. In acknowledging such difficulties and attempting to develop a supportive model, Mishra and Koehler (2006) have drawn on Shulman's ideas on Pedagogical Content Knowledge (PCK) (Shulman, 1986) to draw up a framework to support thinking about the effective integration of technology. This technology, pedagogy and content knowledge (TPACK) framework has been used to develop activities that recognise the interdependence of technology, pedagogy, content and context (Harris, Mishra and Koehler 2009). Our research indicates that even our current understandings are not being effectively communicated to student teachers, who often lack clarity about distinguishing between issues specific to use of the Internet and those more generic in nature. As we have noted, there has not been a long tradition of explicit discussion of pedagogy in general, let alone 'signature pedagogies' or didactics in the English education system. While pedagogy is clearly represented in the HEI context of ITE, it is apparent that even generic discussions of pedagogy are not a regular feature in many school-based contexts. Thus activities that were designed to support pedagogical discussions across ITE partnerships are clearly important and need strengthening further.

There is evidence of the changes made across the institution having an effect. A key element of the work has been the development of approaches that foster collaboration between tutors, student teachers and mentors. The research data from the mentors shows that some still have limited understandings of course processes and resources and activities linked across the schools and HEIs are welcomed. Each institution had different partnership 
arrangements in place and thus expectations in terms of use of the development materials varied. However, preparation and introduction of the materials, with examples of use in HEI sessions, took place in all cases. Mentors were introduced to the project through mentor meetings and training events and encouraged to be involved, but this was not compulsory: the onus was on the student teacher to drive the process.

The evidence shows that in some cases the student teachers were able to work closely with mentors on developing skills in this area and on occasion a mentor took a lead in sharing their own thoughts and expertise. However, even within the case studies for cohort four, engagement was often quite limited. Looking at the cohort as a whole, while practice appeared to be developing, progress was still slow. As ever, time was a key consideration raised in most of the interviews and this suggests further thought be given to the integration of work on the Internet with more generic course needs. Similar considerations suggest that other aspects of courses, such as those focusing on DARTs, might be positioned in the context of Internet work in seeking to avoid potential overload for student teachers.

The approaches developed through the research would appear to have the potential to both improve work in this particular area and to serve as a model for developments in other aspects of teachers' education. However, it is clear that the development of collaborative learning communities, stressed by a number of systematic reviews of effective CPD for teachers in England (e.g. Cordingley et al. 2005), does not come easily. Jamissen and Phelps (2006), in looking at examples of CPD models in the use of ICT in Norway and Australia, stress the role of mentoring and support for reflection within learning communities as vital components of successful models. The Becta $(2009,2010)$ reports cited earlier noted that coordinated planning and CPD were important factors in developing effective use of new 
technologies. Such evidence from models of professional development for in-service teachers accords with that from reviews of effective ITE (e.g. Menter et al. 2010; Zwozdiak-Myers et al. 2010). The ITE model in the English partnerships in this research would seem to have the potential to meet such requirements but our evidence (gleaned from HEI partnerships that have been externally reviewed as very successful ones) shows that there is still work to do in making the structures work well. When they do, there is evidence that the use of ICT in general is likely to remain strong into the first year of teaching (Hammond et al. 2009). The use of a website and possible development of a virtual learning environment to support practice across the institutions have also been supported by teachers within the partnership and might serve to build such collaborative learning communities. Such approaches have been used elsewhere to build learning communities where critical discourse can help to transform practice (e.g. Prestridge 2009). This is one way ITE could become part of the continuing development models suggested in the UK, as well as other national contexts.

This article began by citing evidence that top down models of development often fail to bring about transformations in practice and the evidence from the work presented here is that collaborative models of teacher development can help to bring about such change. Further, Voogt and Plomp (2010), in their review of papers drawing on the outcomes of the influential Second Information Technology in Education Study (SITES), highlight the distinction between pedagogical practices that are 'traditionally important', complying with the requirements of the industrial society, and emerging, innovative pedagogical practices that include an orientation to 'life-long learning' and 'connectedness'. The unevenness of developments across countries and within schools, particularly in relation to more innovative developments, is clear from this work. In striving for innovative changes in the use of ICT it can be argued that what is needed is a high level of support at national level coupled to a more 
decentralised, bottom-up approach to implementation. Drawing on some of the outcomes from SITES 2006, Howie (2010) notes evidence for the success of approaches which focus on teachers and teacher training, and decentralised support networks. The Internet is no longer a new technology. It has taken a long time for many schools to harness the potential and affordances of this technology. This case study of the Internet, taken together with a wealth of research on effective professional development, suggests that strong HEI-schools partnerships, involving processes of collaboration and enquiry, have the potential to support innovation and change.

\section{References}

Becta. 2001. The Secondary School of the Future: A preliminary report to the DfEE. Coventry: Becta.

Becta. 2002. Connecting Schools, Networking People: ICT Practice, Planning and Procurement for the National Grid for Learning. Coventry: Becta.

Becta. 2009. Harnessing Technology Review 2009: The role of technology and its impact on education. Coventry: Becta

Becta, 2010. Harnessing Technology Schools Survey 2010. http://dera.ioe.ac.uk/1544/1/becta_2010_htss_report.pdf

Bishop, K. and Denley, P. 2005. Creating a culture for continuous professional development for science teachers - a view from below. In Pinto, R. and Couso, D. (eds.) Proceedings of the fifth International ESERA Conference pp. 773-777. Barcelona, Spain.

Brabazon, T. 2002. Digital Hemlock . Sydney: University of New South Wales Press. 
Brown, S. and McIntyre, D. 1995. Making Sense of Teaching. Buckingham: Open University Press.

Bullough, R.V., Young, J., Erickson, L., Birrell, J.R., Clark, D.C., Egan, M.W., Berrie, C. F., Hales, V., and Smith, G. 2002. Rethinking field experiences: Partnership teaching vs. single-placement teaching. The Journal of Teacher Education 53, no. 1: 68-80.

Burn, K., Childs, A. and McNicholl, J. 2007. The potential and challenges for studentteachers learning of subject specific pedagogical knowledge within secondary school subject departments. The Curriculum Journal 18, no. 4: 429-445.

Carrington, G 2004. Supervision as a reciprocal learning process. Educational Psychology in Practice 20, no. 1: 31-42.

Clarke, D.B. and Slotta, J.D. 2000. Evaluating media-enhancement and source authority on the internet: the Knowledge Integration Environment International Journal of Science Education, 22: 8, 859-871.

Condie, R. and Munro, B. 2007. The impact of ICT in schools - a landscape review. Coventry: Becta.

Cordes, C. and Miller, E. 2000. Fool's Gold: A critical look at computers in childhood http://drupal6.allianceforchildhood.org/fools_gold.

Cordingley, P., Bell, M., Evans, D., and Firth, A. 2005. The impact of collaborative CPD on classroom teaching and learning. Review: What do teacher impact data tell us about collaborative CPD? In: Research Evidence in Education Library. London: EPPICentre, Social Science Research Unit, Institute of Education, University of London.

Cuckle, P. \& Clarke, S. 2002. Mentoring student-teachers in schools: views and practices and access to ICT. Computer Assisted Learning 18: 330-340. 
DfE. 2012. Teachers' Standards

https://www.education.gov.uk/publications/eOrderingDownload/teachers\%20standard s.pdf

DfEE. 1998. Teaching: High status, high standards requirements for courses of initial teacher training (Circular 4/98). London: DfEE.

DfES. 2001. ImpaCT2: Emerging findings from the evaluation of the impact of information and communications technologies on pupil attainment. Norwich: HMSO.

DfES. 2003a. ICT and attainment: A review of the research literature. Norwich: HMSO.

DfES. 2003b. Survey of Information and Communications Technology in Schools 2003. http://www.dfes.gov.uk/rsgateway/DB/SBU/b000421/index.shtml.

Fullan, M. 2000. The return of large scale educational reform. Journal of Educational Change 1: $15-27$.

Galanouli, D. and McNair, V. 2001. Students' perceptions of ICT-related support in teaching placements. Journal of Computer Assisted Learning 17: 396-408.

Gilles, C and Wilson, J. 2004. Receiving as well as giving: mentors' perceptions of their professional development in one teacher induction programme. Mentoring and Tutoring 12, no. 1: 87-106.

Goodson, I. F. and Mangan, J. M. 1995. Subject cultures and the introduction of classroom computers. British Educational Research Journal 21, no. 5: 613-628.

Hammond, M., Fragkouli, E. Suandi, I., Crosson, C., Ingram, J., Johnston-Wilder, P., Johnston-Wilder, S., Kingston, Y., Pope, M. and Wray, D. 2009. What happens as student teachers who made very good use of ICT during pre-service training enter their first year of teaching? Teacher Development 13, no.2: 93-106. 
Harris, J., Mishra, P. and Koehler, M. 2009. Teachers' technological pedagogical content knowledge and learning activity types: curriculum-based teachnology integration reframed. Journal of Research on Technology in Education 41, no. 4: 393-416.

Harrison, C., Comber, C., Fisher, T., Haw, K., Lewin, C. Lunzer, E., McFarlane, A. Mavers, D., Scrimshaw, P. Somekh, B. and Watling, R. 2003. Impact 2: The Impact of Information and Communications Technology on Pupil learning and Attainment. Norwich: DfES.

Howie, S.J. 2010. ICT-supported pedagogical policies and practices in South Africa and Chile: Emerging economies and realities Journal of Computer Assisted Learning 26, no. 6: 507-522.

Jackson-Mistler, M. and Songer, N.B. 2000. Student Motivation and Internet Technology: Are Students Empowered to Learn Science? Journal of Research in Science Teaching 37, no. 5: 459-479.

Jamissen, G. and Phelps, R. 2006. The role of reflection and mentoring in ICT teacher professional development: dialogue and learning across the hemispheres. Teacher Development 10, no. 3: 293-312.

Jimoyiannis, A. and Komis, V. 2007. Examining teachers' beliefs about ICT in education: Implications of a teacher preparation programme. Teacher Development 11, no. 2: 149-173.

Kirschner, P. and Selinger, M. 2003. The state of affairs of teacher education with respect to information and communications technology. Technology, Pedagogy and Education 12, no. $1: 5-17$.

Kozma, R.B. 2009. Comparative analysis of policies for ICT in Education. In Voogt, J. and Knezek, G. (Eds.) International Handbook of Information Technology in Primary and Secondary Education. New York: Springer. 
Lave, J. and Wenger, E. 1991. Situated Learning: Legitimate Peripheral Participation. Cambridge: Cambridge University Press.

Menter, I., Hulme, M., Dely, E. and Lewin, J. 2010. Literature Review on Teacher Education in the $21^{\text {st }}$ Century. Edinburgh: Education Analytical Services.

Mishra, P., \& Koehler, M. J. 2006. Technological pedagogical content knowledge:

A framework for integrating technology in teacher knowledge. Teachers College Record 108, no. 6: 1017-1054.

NGfL. 2002. Virtual Teachers Centre. http://vtc.ngfl.gov.uk.

(NOF) New Opportunities Fund . 2002. http://www.learningschools.net/NOF.htm.

Nokes, J.D., Bullough, R.V., Egan, W.M., Birrell, J.R. and Hansen, J.M. 2008. The pairedplacement of student teachers: An alternative to traditional placements in secondary school. Teaching and Teacher Education 24, no. 8: 2168-2177.

Osborne, J and Hennessy, S. 2003. Literature review in science education and the role of ICT: Promise, problems and future directions. http://archive.futurelab.org.uk/resources/documents/lit_reviews/Secondary_Science_R eview.pdf.

Papaevripidou, M., Lividjis, M. \& Constantinou, C. 2011. Teachers as learners and designers of ICT-driven science curriculum materials. http://ictforist.oeiizk.waw.pl/upload/PLC_synopsis.pdf.

Poole, P. 2000. Information and Communications Technology in Science Education. In Sears, J. and Sorensen, P. (eds.) Issues in Science Teaching. London: Routledge Falmer.

Prestridge, S. 2009. Teachers' talk in professional development activity that supports change in their ICT pedagogical beliefs and practices. Teacher Development 13, no. 1: 43-55. Rogers, L. and Finlayson, H. 2003. Does ICT in science really work in the classroom? Part 1, The individual teacher experience School Science Review 84 no. 309: 105-111. 
Roth, W-M and Tobin, K. 2004. Coteaching: from praxis to theory. Teachers and Teaching: theory and practice 10, no. 2: 161-179.

Ruthven, K., Hennessy, S. \& Deaney, R. 2005. Incorporating Internet resources into secondary-school teaching, Research Intelligence 90: 4-6.

Schon, D. A. 1987. Educating the Reflective Practitioner San Francisco: Jossey-Bass.

Selinger, M. and Austin, R. 2003. A comparison of the influence of government policy on information and communications technology for teacher training in England and Northern Ireland. Technology, Pedagogy and Education 12, no. 1: 19 - 38.

Shulman, L. 1986. Those who understand: knowledge growth in teaching. Educational Researcher Feb 1986: 4-14

Simon, S. 1980 Why no pedagogy in England? In Leach, J. and Moon, B. 1999. (eds)

Learners and Pedagogy. London: OUP and Paul Chapman

Sorensen, P. and Sears, J. 2005. Collaborative Practice in Initial Teacher Education: the Use of Paired Subject Placements in the School Practicum. International Journal of Learning 14: 619-631

Stake, R.E. 2005. Qualitative Case Studies. In Denzin, N. K. and Lincoln, Y. S. (eds) The SAGE Handbook of Qualitative Research (Third Edition) London: SAGE

TDA. 2007. Professional Standards for Teachers: Why sit still in your career? London: TDA Trucano, M. 2005. Knowledge Maps: ICTs in Education. Washington, DC: infoDev/World Bank

Voogt, J. and Plomb, T. 2010. Innovative ICT-supported pedagogical practices: results from the international study of information technology in education. Journal of Computer Assisted Learning 26, no. 6: 449-452

Vygotsky, L.S. 1987. Thinking and Speech. In Rieber R.W. and Carlton, A.S. The Collected Works of L. S. Vygotsky. New York: Plenum Press. 
White, R.T. 2000. The Knowledge Integration Environment: a commentary on research. International Journal of Science Education 22, no. 8: 873-880.

Zwozdiak-Myers, P., Cameron, K., Mustard, C., Leask, M. and Green, A. 2010. Literature review: analysis of current research, theory and practice in partnership working to identify constituent components of effective ITT partnerships. TDA, Brunel University, West London. http://www.scribd.com/doc/29847198/T35416-Literature-ReviewFinal-February-2010. 